CARPATHIAN J. MATH.

Volume 37 (2021), No. 2,

Pages 273 - 285
Online version at https : //www . carpathian. cunbm . utcluj. ro/

Print Edition: ISSN 1584 - 2851; Online Edition: ISSN 1843 - 4401

DOI: https://doi.org/10.37193/CJM.2021.02.13

Dedicated to Prof. Ioan A. Rus on the occasion of his $85^{\text {th }}$ anniversary

\title{
Existence of common best proximity point for single and multivalued non-self mappings
}

\author{
V. PRAgAdeEsWARAR and R. Gopi
}

\begin{abstract}
In this article, we introduce a new concept called proximal E.A property for single and multivalued mappings. We prove existence of proximally coincidence point for such class of mappings. We provide interesting example which illustrates our main results. Finally, we provide sufficient condition for existence of common best proximity point for this class of mappings.
\end{abstract}

\section{INTRODUCTION}

The study of fixed point plays a vital role in nonlinear analysis. Fixed point theorems deal existence of solution for the equations of the form $f x=x$, which is known as fixed point equation, where $f$ is a mapping from a metric space $(X, d)$ to itself. Suppose $A, B \subset$ $X$ and the mapping $f$ from $A$ to $B$, where $A \cap B=\emptyset$, then the fixed point equation does not have a solution. So it is desirable to determine an approximate solution $x$ such that the error $d(x, f x)$ is minimum. Such a approximate solution is known as best proximity point. The best proximity point theorems provide sufficient conditions to ensure the optimum solution for fixed point equation. We refer the reader for more existence theorems of best proximity point $[3,8,18,20,21,23]$.

Suppose we have two non-self mappings $f, g: A \rightarrow B$, the equations $f x=x$ and $g x=x$ are likely to have no common solution, known as common fixed point of the mappings $f$ and $g$. In this situation, one wants to find approximate solution $x$ such that the errors $d(x, f x)$ and $d(x, g x)$ are minimum for these two fixed point equations, called as common best proximity point of the mappings $f$ and $g$. For detailed analysis on common best proximity point, we direct the reader to see $[5,11,13,14,15,17,19]$.

Because of more applications involved in the study of multivalued mappings in fixed point theory and best proximity point theory, the researchers are focusing the existence of best proximity point for non-self multivalued mappings and existence of common best proximity point for non-self pair of multivalued mappings. For example, in [9], the authors proved the existence of coupled fixed point for multivalued mappings and they applied the result in models in duopoly markets to get a market equilibrium and also to get an equilibrium in aquatic ecosystems. Also, for more analysis and theorems on a best proximity point of multivalued non-self mappings, we suggest [2, 19,22]. In the literature, there are existence results to ensure common fixed point for single valued and multivalued mappings. For example [6, 12]. In 2004, Kamran [12] extended the property (E. A) for a hybrid pair of single and multivalued mappings and proved some coincidence and fixed point theorems for hybrid pairs.

Received: 19.01.2021. In revised form: 17.05.2021. Accepted: 24.05.2021

2010 Mathematics Subject Classification. 47H10, 46B20, 54H25.

Key words and phrases. Best proximity points, fixed points, multivalued mappings.

Corresponding author: V. Pragadeeswarar; v_pragadeeswarar@cb.amrita.edu 
Motivated from the above ideas, we wish to find results on common best proximity point for single and multivalued non-self mappings. In this work, we define the proximal E. A property for single and multivalued non-self mappings and prove existence of proximally coincidence point for this class of mappings. Then we illustrate our theorem by an example. Further, we give sufficient condition to ensure existence of common best proximity point for such a class of mappings.

\section{PRELIMINARIES}

Here we start with some notions:

Let $A, B$ be two subsets of a metric space $(X, d)$.

$$
\begin{aligned}
& \operatorname{dist}(A, B)=d(A, B)=\inf \{d(a, b): a \in A, b \in B\} ; \\
& d(a, B)=\inf \{d(a, b): b \in B\} ; \\
& A_{0}=\left\{a \in A: d\left(a, b^{\prime}\right)=\operatorname{dist}(A, B) \text { for some } b^{\prime} \in B\right\} ; \\
& B_{0}=\left\{b \in B: d\left(a^{\prime}, b\right)=\operatorname{dist}(A, B) \text { for some } a^{\prime} \in A\right\} ; \\
& P(X)=\text { Set of all subsets of } X .
\end{aligned}
$$

A subset $S$ is called proximinal if for each $x \in X$, there exists an element $s \in S$ such that $d(x, s)=d(x, S)=\inf \{d(x, y): y \in S\}$. If $X$ is uniformly convex Banach space, it is well known that, every closed convex subset of $X$ is proximinal.

And we denote $C B(X), C L(X), P C L(X), P C B(X)$ set of all nonempty closed bounded, nonempty closed, nonempty proximinal closed, nonempty proximinal closed bounded subsets of $X$, respectively.

Let $H$ be the Hausdorff metric with respect to $d$, defined by

$$
H(A, B)=\max \left\{\sup _{x \in A} d(x, B), \sup _{y \in B} d(y, A)\right\}
$$

for $A, B \in C B(X)$.

The classical idea of dealing with fixed points for multivalued maps uses the Hausdorff metric introduced in [16]. Another technique is that of an excess of a set beyond another set, introduced in [7]. Both techniques have their advantages.

Definition 2.1. [10] (Kuratowski convergence). Let $(X, d)$ be a metric space and $\left\{A_{n}\right\}, n \in \mathbb{N}$ be a sequence of subsets of $X$. Then

(1) the upper limit or outer limit of the sequence $\left\{A_{n}\right\}, n \in \mathbb{N}$ is a subset of $X$ given by

$$
\lim _{n \rightarrow \infty} \sup A_{n}=\left\{x \in X: \lim _{n \rightarrow \infty} \inf d\left(x, A_{n}\right)=0\right\} ;
$$

(2) the lower limit or inner limit of the sequence $\left\{A_{n}\right\}, n \in \mathbb{N}$ is a subset of $X$ given by

$$
\lim _{n \rightarrow \infty} \inf A_{n}=\left\{x \in X: \lim _{n \rightarrow \infty} \sup d\left(x, A_{n}\right)=0\right\} ;
$$

If $\lim _{n \rightarrow \infty} \sup A_{n}=\lim _{n \rightarrow \infty} \inf A_{n}$, then we say that the limit of $\left\{A_{n}\right\}, n \in \mathbb{N}$ exists and

$$
\lim _{n \rightarrow \infty} \sup A_{n}=\lim _{n \rightarrow \infty} \inf A_{n}=\lim _{n \rightarrow \infty} A_{n} .
$$

Definition 2.2. [10] (Convergence in Hausdorff metric). Let $\left\{A_{n}\right\}$ be a sequence in $C B(X)$ and $A \in C B(X)$. We say that $A_{n}$ converges to $A$ with respect to the Hausdorff metric if and only if $\lim _{n \rightarrow \infty} H\left(A_{n}, A\right)=0$. It is denoted by $A_{n} \stackrel{H}{\rightarrow} A$.

Theorem 2.1. [10] Let $X$ be a metric space, $\left\{A_{n}\right\} \subseteq C B(X)$ and $A \in C B(X)$. Then $A_{n} \stackrel{H}{\rightarrow} A$ implies $A_{n} \rightarrow A$, that is, Hausdorff convergence implies Kuratowski convergence. 
Theorem 2.2. [10] Let $X$ be a metric space and $\left\{A_{n}\right\} \subseteq P(X)$ and $A \in P(X)$. Then prove that

$$
\lim _{n \rightarrow \infty} A_{n}=A \text { if and only if } \lim _{n \rightarrow \infty} d\left(x, A_{n}\right)=0, \forall x \in A .
$$

Definition 2.3. [12] Mappings $f: X \rightarrow X$ and $T: X \rightarrow C B(X)$ are said to satisfy the property (E. A) if there exist a sequence $\left\{x_{n}\right\}$ in $X$, some $t \in X$ and $A \in C B(X)$ such that

$$
T x_{n} \stackrel{H}{\rightarrow} A, \lim _{n \rightarrow \infty} f x_{n}=t \quad \text { and } \quad t \in A .
$$

Theorem 2.3. [12] Let $f$ be a self map of the metric space $(X, d)$ and $T$ be a map from $X$ into $C B(X)$ such that

(1) $f, T$ satisfy the (E. A) property,

(2) for all $x \neq y \in X$ such that

$$
H(T x, T y)<\max \left\{d(f x, f y), \frac{d(f x, T x)+d(f y, T y)}{2}, \frac{d(f y, T x)+d(f x, T y)}{2}\right\} .
$$

If $f(X)$ be a closed subset of $X$, then $f$ and $T$ have a coincidence point.

Definition 2.4. [14] If $A_{0} \neq \emptyset$ then the pair $(A, B)$ is said to have the $P$-property if for any $x_{1}, x_{2} \in A_{0}$ and $y_{1}, y_{2} \in B_{0}$

$$
\left\{\begin{array}{l}
d\left(x_{1}, y_{1}\right)=d(A, B) \\
d\left(x_{2}, y_{2}\right)=d(A, B)
\end{array} \quad \text { implies } \quad d\left(x_{1}, x_{2}\right)=d\left(y_{1}, y_{2}\right) .\right.
$$

\section{EXISTENCE OF PROXIMALLY COINCIDENCE POINT}

In this section, first we introduce the notion proximal E. A property for single and multivalued mappings and we provide interesting example to illustrate our definition.

Definition 3.5. Let $(X, d)$ be metric space and $A, B \subseteq X$. The mappings $f: A \rightarrow B$ and $T: A \rightarrow C B(B)$ are said to satisfy the proximal E.A property if there exist sequences $\left\{x_{n}\right\}$ and $\left\{u_{n}\right\}$ in $A_{0}$ and $V^{\prime} \in C B(B)$ with

$$
\begin{aligned}
d\left(u_{n}, f x_{n}\right) & =d(A, B) \\
V_{n} & =\left\{v: d\left(v, T x_{n}\right)=d(A, B)\right\}
\end{aligned}
$$

such that

$$
V_{n} \stackrel{H}{\rightarrow} V^{\prime}, \lim _{n \rightarrow \infty} u_{n}=u^{\prime} \quad \text { and } \quad u^{\prime} \in V^{\prime} .
$$

Example 3.1. Let $X=\mathbb{R}^{2}$ with Euclidean metric $d$. And we take $A=\{(0, a): 0 \leq a \leq$ $1\}, B=\{(2, b): 0 \leq b \leq 1\}$. So $d(A, B)=2$. Define $f: A \rightarrow B$ by $f(0, a)=(2,1-a)$ and $T: A \rightarrow C B(B)$ by $T(0, a)=\left\{(2, b): a \leq b \leq a+\frac{1}{10}\right\}$ if $a \leq \frac{1}{10}$ and $T(0, a)=\{(2, b)$ : $\left.a-\frac{1}{10} \leq b \leq a\right\}$ if $a>\frac{1}{10}$. By choosing the sequence $x_{n}=\left(0,0.5-\frac{0.5}{n}\right)$, we have for all $n \geq 2, f\left(x_{n}\right)=f\left(0,0.5-\frac{0.5}{n}\right)=\left(2,0.5+\frac{0.5}{n}\right)$. And clearly, $u_{n}=\left(0,0.5+\frac{0.5}{n}\right) \rightarrow(0,0.5)$ as $n \rightarrow \infty$. Since $T\left(0,0.5-\frac{0.5}{n}\right)=\left\{(2, b): 0.4-\frac{0.5}{n} \leq b \leq 0.5-\frac{0.5}{n}\right\}$ implies $V_{n}=\{(0, a)$ : $\left.0.4-\frac{0.5}{n} \leq a \leq 0.5-\frac{0.5}{n}\right\} \rightarrow\{(0, a): 0.4 \leq a \leq 0.5\}=V^{\prime}$ as $n \rightarrow \infty$. Clearly, we get $(0,0.5) \in V^{\prime}$. Hence $f, T$ satisfy the proximal E.A property.

Lemma 3.1. [1] Let $(X, d)$ be a metric space and $B \in C L(X)$. Then, for each $x \in X$ with $d(x, B)>0$ and $q>1$, there exists an element $b \in B$ such that $d(x, b)<q d(x, B)$.

Lemma 3.2. [25] Let $(X, d)$ be a metric space. If $U, V \in C B(X)$ and $u \in U$, then, for each $\varepsilon>0$, there exists $v \in V$ such that $d(u, v) \leq H(U, V)+\varepsilon$.

Here we prove the following two results which help to provide our main theorem. 
Lemma 3.3. Let $(X, d)$ be complete metric space and $A, B \subseteq X$ satisfy the P-property. Let $T: A \rightarrow C L(B)$ be non-self multivalued mapping. Then the set

$$
V_{x}=\{v: d(v, T x)=d(A, B)\}, \forall x \in A
$$

is closed.

Proof. Let $x \in A$. Let $\left\{y_{n}\right\}$ be a sequence in $V_{x}$ such that $y_{n} \rightarrow y$. We claim that $y \in V_{x}$. Since $y_{n} \in V_{x}$ for all $n \in \mathbb{N}$ we get $d\left(y_{n}, T x\right)=d(A, B)$. By continuity of metric $d$ implies $d(y, T x)=d(A, B)$. So $y \in V_{x}$.

Theorem 3.4. Let $X$ be a metric space and $\left\{A_{n}\right\} \subseteq C L(X)$. Suppose

$\lim _{n \rightarrow \infty} d\left(a, A_{n}\right)=0, a \in X$ then there exists subsequence $n_{k}, \forall k \in \mathbb{N}$ with $a_{n_{k}} \in A_{n_{k}}$ such that $a_{n_{k}} \rightarrow a$.

Proof. Let $a \in X$.

Case (1): Suppose $a \in A_{n}$ for finitely many $n$. Clearly, there exists $N \in \mathbb{N}$ such that for all $n \geq N, a \notin A_{n}$. So $d\left(a, A_{n}\right)>0$. Then by Lemma 3.1, there exists a sequence $a_{n} \in A_{n}$, for all $n \geq N$, such that $d\left(a, a_{n}\right)<q d\left(a, A_{n}\right)$ for some $q>1$. As $n \rightarrow \infty$, we obtain $d\left(a, a_{n}\right) \rightarrow 0$ implies $a_{n} \rightarrow a$.

Case (2): Suppose $a \in A_{n}$ for infinitely many $n$. Choose subsequence $n_{1}, n_{2}, \ldots$ such that $a \in A_{n_{k}}, k \in \mathbb{N}$. Now we define sequence $a_{n_{k}}=a, \forall k$. Clearly $a_{n_{k}} \rightarrow a$ as $k \rightarrow \infty$.

Case (3): If $a \notin A_{n}, \forall n \in \mathbb{N}$. Therefore $d\left(a, A_{n}\right)>0$. Again by Lemma 3.1 we obtain $a_{n} \in A_{n}, \forall n$ such that $a_{n} \rightarrow a$, as in the proof of case(1).

Now we define proximally coincidence point and common best proximity point for single and multivalued mappings.

Definition 3.6. Let $(X, d)$ be metric space and $A, B \subseteq X$. A point $a \in A$ is called proximally coincidence point of mappings $f: A \rightarrow B, T: A \rightarrow C B(B)$ if

$$
d(u, f a)=d(A, B)=d(u, T a)
$$

for some $u \in A$.

Definition 3.7. Let $(X, d)$ be metric space and $A, B \subseteq X$. A point $a \in A$ is called common best proximity point of mappings $f: A \rightarrow B, T: A \rightarrow C B(B)$ if

$$
d(a, f a)=d(A, B)=d(a, T a) .
$$

Example 3.2. Let $X=\mathbb{R}^{2}$ with Euclidean metric $d$. And we take $A=\{(0, a): 0 \leq a \leq$ $1\}, B=\{(2, b): 0 \leq b \leq 1\}$. So $d(A, B)=2$. Define $f: A \rightarrow B$ by $f(0, a)=(2,1-a)$ and $T: A \rightarrow C B(B)$ by $T(0, a)=\{(2, b): 0 \leq b \leq 1-a\}$. If we choose the sequence $x_{n}=\left(0, \frac{1}{n}\right)$, we have $f\left(x_{n}\right)=f\left(0, \frac{1}{n}\right)=\left(2,1-\frac{1}{n}\right)$. And clearly, $u_{n}=\left(0,1-\frac{1}{n}\right) \rightarrow(0,1)$ as $n \rightarrow \infty$. Since $T\left(0, \frac{1}{n}\right)=\left\{(2, b): 0 \leq b \leq 1-\frac{1}{n}\right\}$ implies $V_{n}=\left\{(0, a): 0 \leq a \leq 1-\frac{1}{n}\right\} \rightarrow\{(0, a): 0 \leq a \leq$ $1\}=V^{\prime}$ as $n \rightarrow \infty$. Clearly, we get $(0,1) \in V^{\prime}$. Hence $f, T$ satisfy the proximal E.A property.

One can notice the point $(0,0) \in A$ satisfies $d((0,1), f(0,0))=d(A, B)=d((0,1), T(0,0))$. Therefore, $(0,0)$ is proximally coincidence point of $f, T$.

And also we can see $f\left(0, \frac{1}{2}\right)=\left(2, \frac{1}{2}\right)$ and $T\left(0, \frac{1}{2}\right)=\left\{(2, a): 0 \leq a \leq \frac{1}{2}\right\}$. Clearly,

$$
d\left(\left(0, \frac{1}{2}\right), f\left(0, \frac{1}{2}\right)\right)=d(A, B)=d\left(\left(0, \frac{1}{2}\right), T\left(0, \frac{1}{2}\right)\right) .
$$

Then $\left(0, \frac{1}{2}\right)$ is common best proximity point of $f, T$.

Here we define the contractive type condition for non-self mappings $f, T$ in two different ways.

Definition 3.8. Let $(X, d)$ be metric space and $A, B \subseteq X$ and $f: A \rightarrow B, T: A \rightarrow C B(B)$. 
(C) For all $x \neq y \in A$ such that

$H(T x, T y)<\max \left\{d(f x, f y), \frac{d(f x, T x)+d(f y, T y)}{2}, \frac{d(f y, T x)+d(f x, T y)}{2}\right\}$.

(D) For all $x \neq y \in A$ such that

$$
H(U, V)<\max \left\{d\left(u^{\prime}, v^{\prime}\right), \frac{d\left(u^{\prime}, U\right)+d\left(v^{\prime}, V\right)}{2}, \frac{d\left(v^{\prime}, U\right)+d\left(u^{\prime}, V\right)}{2}\right\},
$$

provided

$$
\left\{\begin{array}{l}
d\left(u^{\prime}, f x\right)=d\left(v^{\prime}, f y\right)=d(A, B), \\
U=\{u: d(u, T x)=d(A, B)\}, V=\{v: d(v, T y)=d(A, B)\} .
\end{array}\right.
$$

The class of pair of mappings $f, T$ satisfy the condition $(C)$ is said to be contractive type non-self mappings. And the class of pair of mappings $f, T$ satisfy the condition (D) is said to be proximally contractive type non-self mappings.

The following example agrees condition (C) but not (D).

Example 3.3. Let $X=\mathbb{R}^{2}$ with Euclidean metric $d$. And we take $A=\{(0, a): 0 \leq a \leq 1\}$, $B=\{(-1, b): 0 \leq b \leq 1\} \cup\{(1, b): 0 \leq b \leq 1\}$. So $d(A, B)=1$. Define $f: A \rightarrow B$ by

$$
f(0, a)= \begin{cases}(-1, a) & a \geq 1 / 2 \\ (1, a) & a<1 / 2\end{cases}
$$

and $T: A \rightarrow C B(B)$ by

$$
T(0, a)=\left\{\begin{array}{ll}
\left\{(-1, b): \frac{-a}{2}+\frac{3}{4} \leq b \leq 1\right\} & a \geq 1 / 2 \\
\left\{(-1, b): 0 \leq b \leq \frac{-a}{2}+\frac{3}{4}\right\} & a<1 / 2
\end{array} .\right.
$$

Let $p=(0, x) \in A, q=(0, y) \in A$.

Case 1: If $x, y \geq 1 / 2$ and $x<y$. Then we get $f(0, x)=(-1, x), f(0, y)=(-1, y)$. So $d(f(0, x), f(0, y))=y-x$. And $T(0, x)=\left\{(-1, b): \frac{-x}{2}+\frac{3}{4} \leq b \leq 1\right\}, T(0, y)=\{(-1, b):$ $\left.\frac{-y}{2}+\frac{3}{4} \leq b \leq 1\right\}$. Since $x<y$ implies $\frac{-x}{2}+\frac{3}{4}>\frac{-y}{2}+\frac{3}{4}$. Therefore $H(T(0, x), T(0, y))=\frac{y-x}{2}$. So we have $H(T p, T q)<\max \left\{d(f p, f q), \frac{d(f p, T p)+d(f q, T q)}{2}, \frac{d(f q, T p)+d(f p, T q)}{2}\right\}$.

Case 2: If $x, y<1 / 2$ and $x<y$. Then we get $f(0, x)=(1, x), f(0, y)=(1, y)$. Thus there holds the equality $d(f(0, x), f(0, y))=y-x$. And $T(0, x)=\{(-1, b): 0 \leq b \leq$ $\left.\frac{-x}{2}+\frac{3}{4}\right\}, T(0, y)=\left\{(-1, b): 0 \leq b \leq \frac{-y}{2}+\frac{3}{4}\right\}$. Since $x<y$ implies $\frac{-x}{2}+\frac{3}{4}>\frac{-y}{2}+\frac{3}{4}$. Therefore $H(T(0, x), T(0, y))=\frac{y-x}{2}$. So we have

$$
H(T p, T q)<\max \left\{d(f p, f q), \frac{d(f p, T p)+d(f q, T q)}{2}, \frac{d(f q, T p)+d(f p, T q)}{2}\right\} .
$$

Case 3: If $x<1 / 2$ and $y \geq 1 / 2$. Then we get $f(0, x)=(1, x), f(0, y)=(-1, y)$. And $T(0, x)=\left\{(-1, b): 0 \leq b \leq \frac{-x}{2}+\frac{3}{4}\right\}, T(0, y)=\left\{(-1, b): \frac{-y}{2}+\frac{3}{4} \leq b \leq 1\right\}$. Here one can easily observe that $H(T p, T q) \leq 1$. But $d(f(0, x), f(0, y))>1$. So

$$
H(T p, T q)<\max \left\{d(f p, f q), \frac{d(f p, T p)+d(f q, T q)}{2}, \frac{d(f q, T p)+d(f p, T q)}{2}\right\} .
$$

Therefore the mappings $f, T$ satisfy the contractive condition $(\mathrm{C})$.

Now if we choose $p=\left(0, \frac{51}{100}\right) \in A, q=\left(0, \frac{49}{100}\right) \in A$ then $f\left(0, \frac{51}{100}\right)=\left(-1, \frac{51}{100}\right), f\left(0, \frac{49}{100}\right)=$ $\left(1, \frac{49}{100}\right)$. Therefore, we can obtain $u=\left(0, \frac{51}{100}\right)$ such that $d\left(u, f\left(0, \frac{51}{100}\right)\right)=1$ and we obtain $v=\left(0, \frac{49}{100}\right)$ such that $d\left(v, f\left(0, \frac{49}{100}\right)\right)=1$. Therefore, $d(u, v)=\frac{2}{100}$. Also we get $T\left(0, \frac{51}{100}\right)=$ $\left\{(-1, b): \frac{-51}{200}+\frac{3}{4} \leq b \leq 1\right\}, T\left(0, \frac{49}{100}\right)=\left\{(-1, b): 0 \leq b \leq \frac{-49}{200}+\frac{3}{4}\right\}$. So $U=\left\{(0, b): \frac{99}{200} \leq\right.$ 
$b \leq 1\}, V=\left\{(0, b): 0 \leq b \leq \frac{101}{200}\right\}$. Then $H(U, V)=\frac{99}{200}$. So clearly $d(u, v)<H(U, V)$. So the mappings $f, T$ do not satisfy the condition (D).

Also, the following example agrees condition (D) but not (C).

Example 3.4. Let $X=\mathbb{R}^{2}$ with Euclidean metric $d$. And we take $A=\{(1, a): 0 \leq a \leq$ $1 / 4\} \cup\{(-1, a): 1 / 4 \leq a \leq 1\}, B=\{(0, b): 0 \leq b \leq 1\}$. So $d(A, B)=1$. Define $f: A \rightarrow B$ by $f(-1, a)=(0, a), f(1, a)=(0, a)$ and $T(-1, a)=\left\{(0, b): \frac{-a}{4}+\frac{11}{16} \leq b \leq 1\right\}, T(1, a)=$ $\left\{(0, b): 1 / 4 \leq b \leq \frac{-a}{4}+\frac{11}{16}\right\}$.

Case 1: Let $p=(-1, x) \in A, q=(-1, y) \in A$ and $x<y$. Then we get $f(-1, x)=$ $(0, x), f(-1, y)=(0, y)$. Therefore, we obtain $u=(-1, x)$ such that $d(u, f(-1, x))=1$ and $v=(-1, y)$ such that $d(v, f(-1, y))=1$. So $d(u, v)=y-x$. And $T(-1, x)=\left\{(0, b): \frac{-x}{4}+\right.$ $\left.\frac{11}{16} \leq b \leq 1\right\}, T(-1, y)=\left\{(0, b): \frac{-y}{4}+\frac{11}{16} \leq b \leq 1\right\}$. Therefore $U=\left\{(-1, b): \frac{-x}{4}+\frac{11}{16} \leq b \leq\right.$ $1\}$ and $V=\left\{(-1, b): \frac{-y}{4}+\frac{11}{16} \leq b \leq 1\right\}$. Since $x<y$ implies $\frac{-x}{4}+\frac{11}{16}>\frac{-y}{4}+\frac{11}{16}$. Therefore $H(U, V)=\frac{y-x}{4}$. So we have $H(U, V)<\max \left\{d(u, v), \frac{d(u, U)+d(v, V)}{2}, \frac{d(v, U)+d(u, V)}{2}\right\}$.

Case 2: Let $p=(1, x) \in A, q=(1, y) \in A$ and $x<y$. Then we get $f(1, x)=(0, x), f(1, y)=$ $(0, y)$. Therefore, we obtain $u=(1, x)$ such that $d(u, f(1, x))=1$ and $v=(1, y)$ such that $d(v, f(1, y))=1$. So $d(u, v)=y-x$. And $T(1, x)=\left\{(0, b): 1 / 4 \leq b \leq \frac{-x}{4}+\frac{11}{16}\right\}, T(1, y)=$ $\left\{(0, b): 1 / 4 \leq b \leq \frac{-y}{4}+\frac{11}{16}\right\}$. Therefore $U=\left\{(-1, b): 1 / 4 \leq b \leq \frac{-x}{4}+\frac{11}{16}\right\}$ and $V=$ $\left\{(-1, b): 1 / 4 \leq b \leq \frac{-y}{4}+\frac{11}{16}\right\}$. Since $x<y$ implies $\frac{-x}{4}+\frac{11}{16}>\frac{-y}{4}+\frac{11}{16}$. Therefore $H(U, V)=\frac{y-x}{4}$. So we have $H(U, V)<\max \left\{d(u, v), \frac{d(u, U)+d(v, V)}{2}, \frac{d(v, U)+d(u, V)}{2}\right\}$.

Case 3: If $(1, x) \in A$ and $(-1, y) \in A$. Then we get $f(1, x)=(0, x), f(-1, y)=(0, y)$. Therefore, we obtain $u=(1, x)$ such that $d(u, f(1, x))=1$ and $v=(-1, y)$ such that $d(v, f(-1, y))=1$. So $d(u, v)>1$. And $T(1, x)=\left\{(0, b): 1 / 4 \leq b \leq \frac{-x}{4}+\frac{11}{16}\right\}, T(-1, y)=$ $\left\{(0, b): \frac{-y}{4}+\frac{11}{16} \leq b \leq 1\right\}$. Therefore, we obtain $U=\left\{(-1, b): 1 / 4 \leq b \leq \frac{-x}{4}+\frac{11}{16}\right\}, V=$ $\left\{(-1, b): \frac{-y}{4}+\frac{11}{16} \leq b \leq 1\right\}$. Here one can easily observe that $H(U, V) \leq 1$. But $d(u, v)>1$. So $H(U, V)<\max \left\{d(u, v), \frac{d(u, U)+d(v, V)}{2}, \frac{d(v, U)+d(u, V)}{2}\right\}$. Therefore the mappings $f, T$ satisfy the contractive condition $(\mathrm{D})$.

Now if we choose $p=\left(-1, \frac{26}{100}\right) \in A, q=\left(1, \frac{24}{100}\right) \in A$ then $f\left(-1, \frac{26}{100}\right)=\left(0, \frac{26}{100}\right), f\left(1, \frac{24}{100}\right)=$ $\left(0, \frac{24}{100}\right)$. Therefore, $d(f p, f q)=\frac{2}{100}$. Also we get

$T\left(-1, \frac{26}{100}\right)=\left\{(0, b): \frac{-26}{400}+\frac{11}{16} \leq b \leq 1\right\}, T\left(1, \frac{24}{100}\right)=\left\{(0, b): 1 / 4 \leq b \leq \frac{-24}{400}+\frac{11}{16}\right\}$. Then $H(T p, T q)=\frac{149}{400}$. Now by simple calculations we obtain $d(f p, f q)=\frac{2}{100}, d(f p, T p)=$ $\frac{145}{400}, d(f q, T q)=\frac{1}{100}, d(f q, T p)=\frac{153}{400}, d(f p, T q)=0$.

It shows $\max \left\{d(f p, f q), \frac{d(f p, T p)+d(f q, T q)}{2}, \frac{d(f q, T p)+d(f p, T q)}{2}\right\}=\frac{d(f q, T p)+d(f p, T q)}{2}$.

But $\frac{d(f q, T p)+d(f p, T q)}{2}<H(T p, T q)$. Therefore, the mappings $f, T$ do not satisfy the condition $(\mathrm{C})$.

Now we prove our main theorem of this article with the assumption of condition $(C)$.

Theorem 3.5. Let $(X, d)$ be complete metric space and $A, B \subseteq X$ satisfy the P-property. Assume $A_{0}$ is compact. Let $f: A \rightarrow B$ and $T: A \rightarrow P C B(B)$ be mappings such that

(1) $f, T$ satisfy the proximal E.A property,

(2) for all $x \neq y \in A$ such that

$$
H(T x, T y)<\max \left\{d(f x, f y), \frac{d(f x, T x)+d(f y, T y)}{2}, \frac{d(f y, T x)+d(f x, T y)}{2}\right\} .
$$

If $f\left(A_{0}\right)$ is closed subset of $B_{0}$ and $T a \subseteq B_{0}, \forall a \in A_{0}$ then $f, T$ have a proximally coincidence point. 
Proof. Since the pair $(f, T)$ satisfies the proximal E.A property then there exist a sequence $\left\{x_{n}\right\} \in A_{0}$ and $V^{\prime} \in C B(B)$ with

$$
\begin{aligned}
d\left(u_{n}, f x_{n}\right) & =d(A, B) \\
V_{n} & =\left\{v: d\left(v, T x_{n}\right)=d(A, B)\right\}
\end{aligned}
$$

such that

$$
\lim _{n \rightarrow \infty} u_{n}=u^{\prime} \in V^{\prime}=\lim _{n \stackrel{H}{\longrightarrow} \infty} V_{n} .
$$

By (3.1) and by the $P$-property we obtain $d\left(u_{n}, u_{m}\right)=d\left(f x_{n}, f x_{m}\right)$. By the convergence of $\left\{u_{n}\right\}$ implies Cauchy. Then $\left\{f x_{n}\right\}$ is Cauchy. Since $X$ is complete we get $f x_{n} \rightarrow t$ for some $t \in X$. Since $f\left(A_{0}\right)$ is closed subset of $B_{0}$ there exists $a \in A_{0}$ such that $t=f(a) \in f\left(A_{0}\right)$. Then $f(a) \in B_{0}$. So there exists $u \in A_{0}$ such that $d(u, f a)=d(A, B)$. Therefore, from (3.1) as $n \rightarrow \infty$, we get

$$
d\left(u^{\prime}, f a\right)=d(A, B) .
$$

By the $P$-property, $u=u^{\prime} \in V^{\prime}$. Now for this $a \in A_{0}$, define $D=\{x: d(x, T a)=d(A, B)\}$. Since $T a \subseteq B_{0}$, we get $D \neq \emptyset$. To show $a$ is proximally coincidence point of $f$ and $T$, it is enough to claim $u \in D$. From Theorems 2.1,2.2 and 3.4 there exists a sequence $v_{n} \in V_{n}$ such that $v_{n} \rightarrow u^{\prime}$. Because of $v_{n} \in V_{n}$, we have

$$
d\left(v_{n}, T x_{n}\right)=d(A, B) .
$$

Since $T x_{n}$ is proximinal then there exists $x_{n}^{\prime} \in T x_{n}$ such that

$$
d\left(v_{n}, x_{n}^{\prime}\right)=d(A, B) .
$$

By Lemma 3.2, for all $x_{n}^{\prime} \in T x_{n}$ and for $\frac{1}{n}>0, n \in \mathbb{N}$ there exists $a_{n}^{\prime} \in T a$ such that $d\left(x_{n}^{\prime}, a_{n}^{\prime}\right) \leq H\left(T x_{n}, T a\right)+1 / n$. One can note that $a_{n}^{\prime} \in B_{0}, \forall n$. So there exists $c_{n}^{\prime} \in A_{0}$ such that

$$
d\left(c_{n}^{\prime}, a_{n}^{\prime}\right)=d(A, B) .
$$

By the $P$-property, we obtain $d\left(v_{n}, c_{n}^{\prime}\right)=d\left(x_{n}^{\prime}, a_{n}^{\prime}\right)$. Since $A_{0}$ is compact there exists a subsequence $\left\{c_{n_{k}}^{\prime}\right\}$ of $\left\{c_{n}^{\prime}\right\}$ such that $c_{n_{k}}^{\prime} \rightarrow c^{\prime} \in A_{0}$ as $k \rightarrow \infty$. Then by (2), we derive

$$
\begin{aligned}
& d\left(v_{n_{k}}, c_{n_{k}}^{\prime}\right) \\
= & d\left(x_{n_{k}}^{\prime}, a_{n_{k}}^{\prime}\right) \\
\leq & H\left(T x_{n_{k}}, T a\right)+1 / n_{k} \\
< & \max \left\{d\left(f x_{n_{k}}, f a\right), \frac{d\left(f x_{n_{k}}, T x_{n_{k}}\right)+d(f a, T a)}{2}, \frac{d\left(f a, T x_{n_{k}}\right)+d\left(f x_{n_{k}}, T a\right)}{2}\right\}+1 / n_{k} .
\end{aligned}
$$

From (3.1) and (3.4) and using the $P$-property, we obtain $d\left(u_{n_{k}}, v_{n_{k}}\right)=d\left(f x_{n_{k}}, x_{n_{k}}^{\prime}\right)$. And since $x_{n_{k}}^{\prime} \in T x_{n_{k}}$ implies $d\left(f x_{n_{k}}, x_{n_{k}}^{\prime}\right) \geq d\left(f x_{n_{k}}, T x_{n_{k}}\right)$.

Then $d\left(u_{n_{k}}, v_{n_{k}}\right) \geq d\left(f x_{n_{k}}, T x_{n_{k}}\right)$. Now from (3.3) and (3.5) and using the P-property, we derive

$$
d\left(u^{\prime}, c_{n_{k}}^{\prime}\right)=d\left(f a, a_{n_{k}}^{\prime}\right) \geq d(f a, T a) .
$$

Again from (3.3) and (3.4) and by the $P$-property, we get

$$
d\left(u^{\prime}, v_{n_{k}}\right)=d\left(f a, x_{n_{k}}^{\prime}\right) \geq d\left(f a, T x_{n_{k}}\right) .
$$

Also from (3.5) and (3.1) and by the $P$-property, we obtain

$$
d\left(c_{n_{k}}^{\prime}, u_{n_{k}}\right)=d\left(a_{n_{k}}^{\prime}, f x_{n_{k}}\right) \geq d\left(T a, f x_{n_{k}}\right) .
$$

And also from (3.1) and (3.3) and using the $P$-property

$$
d\left(f x_{n_{k}}, f a\right)=d\left(u_{n_{k}}, u^{\prime}\right) .
$$


Therefore, we derive

$d\left(v_{n_{k}}, c_{n_{k}}^{\prime}\right)<\max \left\{d\left(u_{n_{k}}, u^{\prime}\right), \frac{d\left(u_{n_{k}}, v_{n_{k}}\right)+d\left(u^{\prime}, c_{n_{k}}^{\prime}\right)}{2}, \frac{d\left(u^{\prime}, v_{n_{k}}\right)+d\left(c_{n_{k}}^{\prime}, u_{n_{k}}\right)}{2}\right\}+1 / n_{k}$.

As $k \rightarrow \infty$, we get

$$
\begin{aligned}
d\left(u^{\prime}, c^{\prime}\right) & \leq \max \left\{d\left(u^{\prime}, u^{\prime}\right), \frac{d\left(u^{\prime}, u^{\prime}\right)+d\left(u^{\prime}, c^{\prime}\right)}{2}, \frac{d\left(u^{\prime}, u^{\prime}\right)+d\left(c^{\prime}, u^{\prime}\right)}{2}\right\} \\
& =\frac{d\left(c^{\prime}, u^{\prime}\right)}{2} .
\end{aligned}
$$

Therefore, we obtain $d\left(u^{\prime}, c^{\prime}\right) \leq \frac{d\left(u^{\prime}, c^{\prime}\right)}{2}$. This implies $d\left(u^{\prime}, c^{\prime}\right)=0$. So $u^{\prime}=c^{\prime}$. Now we prove $c^{\prime} \in D$. From (3.5), $d\left(c_{n_{k}}^{\prime}, a_{n_{k}}^{\prime}\right)=d(A, B)$. This implies $d\left(c_{n_{k}}^{\prime}, T a\right)=d(A, B)$. By continuity of $d$ gives $d\left(c^{\prime}, T a\right)=d(A, B)$ as $k \rightarrow \infty$. Then $c^{\prime} \in D$. Hence proved.

The following example support the above theorem.

Example 3.5. Let $X=\mathbb{R}^{2}$ with Euclidean metric $d$. And we take $A=\{(0, a): 0 \leq a \leq$ $1\}, B=\{(2, b): 0 \leq b \leq 1\}$. So $d(A, B)=2$. Define $f: A \rightarrow B$ by $f(0, a)=(2,1-a)$ and $T: A \rightarrow P C B(B)$ by $T(0, a)=\left\{(2, b): 0 \leq b \leq \frac{1-a}{2}\right\}$. If we choose the sequence $x_{n}=\left(0,1-\frac{1}{n}\right)$, we have $f\left(x_{n}\right)=f\left(0,1-\frac{1}{n}\right)=\left(2, \frac{1}{n}\right)$. And clearly, $u_{n}=\left(0, \frac{1}{n}\right) \rightarrow(0,0)$ as $n \rightarrow \infty$. Since $T\left(0,1-\frac{1}{n}\right)=\left\{(2, b): 0 \leq b \leq \frac{1}{2 n}\right\}$ implies $V_{n}=\left\{(0, a): 0 \leq a \leq \frac{1}{2 n}\right\} \rightarrow$ $\{(0, a): 0 \leq a \leq 0\}=\{(0,0)\}=V^{\prime}$ as $n \rightarrow \infty$. Clearly, we get $(0,0) \in V^{\prime}$. Hence $f, T$ satisfy the proximal E.A property. Now, for $x=(0, a), y=(0, b)$ with $a<b$, we have $T(0, a)=\left\{(2, x): 0 \leq x \leq \frac{1-a}{2}\right\}, T(0, b)=\left\{(2, x): 0 \leq x \leq \frac{1-b}{2}\right\}$. Since $a<b$ implies that $\frac{1-a}{2}>\frac{1-b}{2}$. Therefore, we get $T(0, b) \subseteq T(0, a)$. Then $H(T(0, a), T(0, b))=\frac{b-a}{2}$. And $f(0, a)=(2,1-a), f(0, b)=(2,1-b)$. So clearly $d(f(0, a), f(0, b))=b-a$. Then the inequality

$$
H(T x, T y)<\max \left\{d(f x, f y), \frac{d(f x, T x)+d(f y, T y)}{2}, \frac{d(f y, T x)+d(f x, T y)}{2}\right\}
$$

follows. So by above theorem the point $(0,1) \in A$ satisfies $d((0,0), f(0,1))=d(A, B)=$ $d((0,0), T(0,1))$. Therefore, $(0,1)$ is proximally coincidence point of $f, T$.

In the above theorem, by assuming the proximally contractive type condition (D), instead of the condition (C), we can prove the existence result of coincidence point without assumtion of compactness on $A_{0}$.

Theorem 3.6. Let $(X, d)$ be complete metric space and $A, B \subseteq X$ satisfy the P-property. Let $f: A \rightarrow B$ and $T: A \rightarrow C B(B)$ be mappings satisfies

(1) $f, T$ satisfy the proximal E.A property,

(2) for all $x \neq y \in A$ such that

$$
H(U, V)<\max \left\{d\left(u^{\prime}, v^{\prime}\right), \frac{d\left(u^{\prime}, U\right)+d\left(v^{\prime}, V\right)}{2}, \frac{d\left(v^{\prime}, U\right)+d\left(u^{\prime}, V\right)}{2}\right\},
$$

provided

$$
\left\{\begin{array}{l}
d\left(u^{\prime}, f x\right)=d\left(v^{\prime}, f y\right)=d(A, B) \\
U=\{u: d(u, T x)=d(A, B)\}, V=\{v: d(v, T y)=d(A, B)\} .
\end{array}\right.
$$

If $f\left(A_{0}\right)$ is closed and $T a \cap B_{0} \neq \emptyset, \forall a \in A_{0}$ then $f, T$ have a proximally coincidence point. 
Proof. Since the pair $(f, T)$ satisfies the proximal E.A property then there exist a sequence $\left\{x_{n}\right\} \in A_{0}$ and $V^{\prime} \in C B(B)$ with

$$
\begin{aligned}
d\left(u_{n}, f x_{n}\right) & =d(A, B) \\
V_{n} & =\left\{v: d\left(v, T x_{n}\right)=d(A, B)\right\}
\end{aligned}
$$

such that

$$
\lim _{n \rightarrow \infty} u_{n}=u^{\prime} \in V^{\prime}=\lim _{n \stackrel{H}{\longrightarrow} \infty} V_{n} .
$$

By (3.10) and by the $P$-property we obtain $d\left(u_{n}, u_{m}\right)=d\left(f x_{n}, f x_{m}\right)$. By the convergence of $\left\{u_{n}\right\}$ implies Cauchy. Then $\left\{f x_{n}\right\}$ is Cauchy. Since $X$ is complete we get $f x_{n} \rightarrow t$ for some $t \in X$. Since $f\left(A_{0}\right)$ is closed then there exists $a \in A_{0}$ such that $t=f(a) \in f\left(A_{0}\right)$. Therefore, from (3.10) as $n \rightarrow \infty$, we get

$$
d\left(u^{\prime}, f a\right)=d(A, B) .
$$

Now for this $a \in A_{0}$, define $D=\{x: d(x, T a)=d(A, B)\}$. By Lemma 3.3, $D$ is closed. Since $\operatorname{Ta} \cap B_{0} \neq \emptyset$, we get $D \neq \emptyset$. To show $a$ is proximally coincidence point of $f$ and $T$, it is enough to claim $u^{\prime} \in D$. Now we derive

$$
H\left(V_{n}, D\right)<\max \left\{d\left(u_{n}, u^{\prime}\right), \frac{d\left(u_{n}, V_{n}\right)+d\left(u^{\prime}, D\right)}{2}, \frac{d\left(u^{\prime}, V_{n}\right)+d\left(u_{n}, D\right)}{2}\right\} .
$$

As $n \rightarrow \infty$, we get

$$
\begin{aligned}
H\left(V^{\prime}, D\right) & \leq \max \left\{d\left(u^{\prime}, u^{\prime}\right), \frac{d\left(u^{\prime}, V^{\prime}\right)+d\left(u^{\prime}, D\right)}{2}, \frac{d\left(u^{\prime}, V^{\prime}\right)+d\left(u^{\prime}, D\right)}{2}\right\} \\
& =\frac{d\left(u^{\prime}, V^{\prime}\right)+d\left(u^{\prime}, D\right)}{2} .
\end{aligned}
$$

Since $u^{\prime} \in V^{\prime}$, we obtain $d\left(u^{\prime}, D\right) \leq \frac{d\left(u^{\prime}, D\right)}{2}$, which implies that $d\left(u^{\prime}, D\right)=0$. Since $D$ is closed we get $u^{\prime} \in D$.

Example 3.6. Let $X=\mathbb{R}^{2}$ with Euclidean metric $d$. And we take $A=\{(0, a): 1 \leq$ $a<\infty\}, B=\{(2, b): 1 \leq b<\infty\}$. So $d(A, B)=2$. Define $f: A \rightarrow B$ by $f(0, a)=$ $\left(2, a^{2}\right)$ and $T: A \rightarrow P C B(B)$ by $T(0, a)=\{(2, b): 1 \leq b \leq a+1\}$. If we choose the sequence $x_{n}=\left(0,1+\frac{1}{n}\right)$, we have $f\left(x_{n}\right)=f\left(0,1+\frac{1}{n}\right)=\left(2,\left(1+\frac{1}{n}\right)^{2}\right)$. And clearly, $u_{n}=\left(0,\left(1+\frac{1}{n}\right)^{2}\right) \rightarrow(0,1)$ as $n \rightarrow \infty$. Since $T\left(0,1+\frac{1}{n}\right)=\left\{(2, b): 1 \leq b \leq 2+\frac{1}{n}\right\}$ implies $V_{n}=\left\{(0, a): 1 \leq a \leq 2+\frac{1}{n}\right\} \rightarrow\{(0, a): 1 \leq a \leq 2\}=V^{\prime}$ as $n \rightarrow \infty$. Clearly, we get $(0,1) \in V^{\prime}$. Hence $f, T$ satisfy the proximal E.A property.

Now, for $x=(0, a), y=(0, b)$ with $a<b$, we have $T(0, a)=\{(2, x): 1 \leq x \leq 1+$ $a\}, T(0, b)=\{(2, x): 1 \leq x \leq 1+b\}$. So $U=\{(0, x): 1 \leq x \leq 1+a\}, V=\{(0, x): 1 \leq x \leq$ $1+b\}$. And $f(0, a)=\left(2, a^{2}\right), f(0, b)=\left(2, b^{2}\right)$. So $u^{\prime}=\left(0, a^{2}\right), v^{\prime}=\left(0, b^{2}\right)$. Therefore, we get $U \subseteq V$. Then $H(U, V)=b-a$. And clearly $d\left(u^{\prime}, v^{\prime}\right)=b^{2}-a^{2}$. Since $a, b \geq 1$ we have $b-a<b^{2}-a^{2}$ then the inequality

$$
H(U, V)<\max \left\{d\left(u^{\prime}, v^{\prime}\right), \frac{d\left(u^{\prime}, U\right)+d\left(v^{\prime}, V\right)}{2}, \frac{d\left(v^{\prime}, U\right)+d\left(u^{\prime}, V\right)}{2}\right\}
$$

follows. So by above theorem the point $(0,1) \in A$ satisfies $d((0,1), f(0,1))=d(A, B)=$ $d((0,1), T(0,1))$. Therefore, $(0,1)$ is proximally coincidence point of $f, T$. 


\section{EXISTENCE OF COMMON BEST PROXIMITY POINT}

In this section, we provide sufficient condition for existence of common best proximity point for single and multivalued non-self mappings. First we recall the Definition and a Theorem from [12].

Definition 4.9. [12]Let $T: X \rightarrow C B(X)$. The map $f: X \rightarrow X$ is said to be $T$-weakly commuting at $x \in X$ if $f f x \in T f x$.

Theorem 4.7. [12] Let $f$ be a self map of the metric space $(X, d)$ and $T$ be a map from $X$ into $C B(X)$ such that

(1) $f, T$ satisfy the (E.A) property,

(2) for all $x \neq y \in A$ such that

$H(T x, T y)<\max \left\{d(f x, f y), \frac{d(f x, T x)+d(f y, T y)}{2}, \frac{d(f y, T x)+d(f x, T y)}{2}\right\}$.

(3) $f$ is $T$-weakly commuting at $v$ and $f f v=$ fv for $v \in C(f, T):=$ set of coincidence points of $f$ and $T$.

If $f(X)$ be a closed subset of $X$, then $f$ and $T$ have a common best proximity point.

Now we extend the Definition 4.9 to the case of single and multivalued non-self mappings.

Definition 4.10. Let $T: A \rightarrow C B(B)$. The map $f: A \rightarrow B$ is said to be proximally $T$-weakly commuting at $x \in A$ if

$$
\left\{\begin{array}{l}
d(u, f x)=d(A, B) \\
d\left(u^{\prime}, f u\right)=d(A, B)
\end{array} \text { then } \quad d\left(u^{\prime}, T u\right)=d(A, B)\right.
$$

for some $u, u^{\prime} \in A$.

Example 4.7. Let $X=\mathbb{R}^{2}$ with Euclidean metric $d$.

Let $A=\{(1,0),(2,0),(3,0),(4,0)\}$ and $B=\{(1,1),(2,1),(3,1),(4,1)\}$. So $d(A, B)=1$. Define $f: A \rightarrow B$ by

$$
f(1,0)=(4,1), f(2,0)=(3,1), f(3,0)=(2,1), f(4,0)=(1,1),
$$

and $T: A \rightarrow C B(B)$ by $T(1,0)=\{(3,1),(4,1)\}, T(2,0)=\{(2,1),(4,1)\}$, $T(3,0)=\{(1,1),(3,1)\}, T(4,0)=\{(1,1),(4,1)\}$. Then one can notice that $f$ is proximally $T$-weakly commuting at the points $(1,0),(4,0) \in A$.

The following theorem gives sufficient condition for existence of common best proximity point for single and multivalued mappings which extends the Theorem 4.7 proved in [12].

Theorem 4.8. Let $(X, d)$ be complete metric space and $A, B \subseteq X$ satisfy the P-property. Assume $A_{0}$ is compact. Let $f: A \rightarrow B$ and $T: A \rightarrow P C B(B)$ be mappings such that

(1) $f, T$ satisfy the proximal E. A property,

(2) for all $x \neq y \in A$ such that

$H(T x, T y)<\max \left\{d(f x, f y), \frac{d(f x, T x)+d(f y, T y)}{2}, \frac{d(f y, T x)+d(f x, T y)}{2}\right\}$,

(3) $f$ is proximally $T$-weakly commuting at $v$ and if $d\left(v^{\prime}, f v\right)=d(A, B)$ then $d\left(v^{\prime}, f v^{\prime}\right)=d(A, B)$ for $v \in P C(f, T):=$ set of proximally coincidence point of $f$ and $T$. 
If $f\left(A_{0}\right)$ is closed subset of $B_{0}$ and $T a \subseteq B_{0}, \forall a \in A_{0}$ then $f, T$ have a common best proximity point.

Proof. By above theorem there exist $a \in A_{0}$ and $u \in D$ such that $d(u, f a)=d(A, B)$. Since $u \in D$, we have $d(u, T a)=d(A, B)$. Then by (3) we get $d(u, f u)=d(A, B)$. Because of $f$ is $T$-weakly commutative at $a$ implies that $d(u, T u)=d(A, B)$, hence the theorem follows.

Example 4.8. Let $X=\mathbb{R}^{2}$ with Euclidean metric $d$. Let $A=\{(x, 1): 0 \leq x \leq 1\}$ and $B=\{(x,-1): 0 \leq x \leq 1\}$. Define $f: A \rightarrow B$ by $f(x, 1)=\left(x^{2},-1\right)$, and $T: A \rightarrow P C B(B)$ by $T(x, 1)=\left\{(y,-1): y \in\left[0, \frac{x^{2}}{2}\right]\right\}$. We choose the sequence $x_{n}=\left(\frac{1}{n}, 1\right)$ for all $n$. Then we get $f x_{n}=f\left(\frac{1}{n}, 1\right)=\left(\frac{1}{n^{2}},-1\right), \forall n$ and $T x_{n}=T\left(\frac{1}{n}, 1\right)=\left\{(y,-1): y \in\left[0, \frac{1}{2 n^{2}}\right]\right\}$. Therefore, we obtain $u_{n}=\left(\frac{1}{n^{2}}, 1\right), \forall n$ and $V_{n}=\left\{(y, 1): y \in\left[0, \frac{1}{2 n^{2}}\right]\right\}$. So, we conclude that

$$
\lim _{n \rightarrow \infty} u_{n} \in \lim _{n \stackrel{H}{\longrightarrow} \infty} V_{n} \text {. }
$$

Hence $f, T$ satisfy the proximal E.A property. Also, for $x \neq y$ with $x<y$, we get $H(T(x, 1), T(y, 1))=\left|\frac{y^{2}}{2}-\frac{x^{2}}{2}\right|$. And $d(f(x, 1), f(y, 1))=\left|y^{2}-x^{2}\right|$. This implies that

$$
\begin{aligned}
H(T(x, 1), T(y, 1))< & \max \left\{d(f(x, 1), f(y, 1)), \frac{d(f(x, 1), T(x, 1))+d(f(y, 1), T(y, 1))}{2},\right. \\
& \left.\frac{d(f(y, 1), T(x, 1))+d(f(x, 1), T(y, 1))}{2}\right\} .
\end{aligned}
$$

Also, one can easily identify the condition (3) of Theorem 4.8, with $f$ is proximally $T$ weakly commuting at $(0,1)$. Then by Theorem 4.8 , we conclude $(0,1)$ is a common best proximity point of $f, T$.

Theorem 4.9. Let $(X, d)$ be complete metric space and $A, B \subseteq X$ satisfy the P-property. Let $f: A \rightarrow B$ and $T: A \rightarrow C B(B)$ be mappings satisfies

(1) $f, T$ satisfy the proximal E.A property,

(2) for all $x \neq y \in A$ such that

$$
H(U, V)<\max \left\{d\left(u^{\prime}, v^{\prime}\right), \frac{d\left(u^{\prime}, U\right)+d\left(v^{\prime}, V\right)}{2}, \frac{d\left(v^{\prime}, U\right)+d\left(u^{\prime}, V\right)}{2}\right\},
$$

provided

$$
\left\{\begin{array}{l}
d\left(u^{\prime}, f x\right)=d\left(v^{\prime}, f y\right)=d(A, B), \\
U=\{u: d(u, T x)=d(A, B)\}, V=\{v: d(v, T y)=d(A, B)\},
\end{array}\right.
$$

(3) $f$ is proximally $T$-weakly commuting at $v$ and if

$d\left(v^{\prime}, f v\right)=d(A, B)$ then $d\left(v^{\prime}, f v^{\prime}\right)=d(A, B)$ for $v \in P C(f, T):=$ set of proximally coincidence point of $f$ and $T$.

If $f\left(A_{0}\right)$ is closed and $T a \cap B_{0} \neq \emptyset, \forall a \in A_{0}$ then $f, T$ have a common best proximity point.

Proof. The proof follows as above theorem.

Example 4.9. Let $X=\mathbb{R}^{2}$ with Euclidean metric $d$. Let $A=\{(0, x): 0 \leq x \leq 4\}$ and $B=\{(2, x): 0 \leq x \leq 4\}$. Define $f: A \rightarrow B$ by $f(0, x)=(2, x)$, and $T: A \rightarrow P C B(B)$ by $T(0, x)=\{(2, \ln (1+y)): y \in[0, x]\}$. We choose the sequence $x_{n}=\left(0, \frac{1}{n}\right)$ for all $n$. Then we get $f x_{n}=f\left(0, \frac{1}{n}\right)=\left(2, \frac{1}{n}\right), \forall n$ and $T x_{n}=T\left(0, \frac{1}{n}\right)=\left\{(2, \ln (1+y)): y \in\left[0, \frac{1}{n}\right]\right\}$. Therefore, we obtain $u_{n}=\left(0, \frac{1}{n}\right), \forall n$ and $V_{n}=\left\{(0, \ln (1+y)): y \in\left[0, \frac{1}{n}\right]\right\}$. So, we conclude that

$$
\lim _{n \rightarrow \infty} u_{n} \in \lim _{n \stackrel{H}{\rightarrow} \infty} V_{n}
$$


Hence $f, T$ satisfy the proximal E.A property. Also, for $x \neq y$ with $x<y$, we get $H(U, V)=|\ln (1+y)-\ln (1+x)|$, and $d\left(u^{\prime}, v^{\prime}\right)=|y-x|$ where $u^{\prime}, v^{\prime}, U, V$ are as in Theorem 4.9. This implies that

$$
H(U, V)<\max \left\{d\left(u^{\prime}, v^{\prime}\right), \frac{d\left(u^{\prime}, U\right)+d\left(v^{\prime}, V\right)}{2}, \frac{d\left(v^{\prime}, U\right)+d\left(u^{\prime}, V\right)}{2}\right\} .
$$

Also, one can easily identify the condition (3) of Theorem 4.9, with $f$ is proximally $T$ weakly commuting at $(0,0)$. Then by Theorem 4.9 , we conclude $(0,0)$ is a common best proximity point of $f, T$.

Conflict of interests. The authors have no conflict of interests regarding the publication of this paper

Acknowledgements. The authors would like to thank the National Board for Higher Mathematics (NBHM), DAE, Govt. of India for providing a financial support under the grant no. 02011/22/2017/R\&D II/14080.

\section{REFERENCES}

[1] Ali, MU. and Kamran, T., On $\left(\alpha^{*}, \psi\right)$-contractive multi-valued mappings, Fixed Point Theory Appl., 2013, 2013:137, 7 pp.

[2] Al-Thagafi, MA. and Shahzad, N., Best proximity pairs and equilibrium pairs for Kakutani multimaps, Nonlinear Anal., 70 (2009), No. 3, 1209-1216

[3] Anthony Eldred, A. and Veeramani, P., Existence and convergence of best proximity points, J. Math. Anal. Appl., 323 (2006), No. 2, 1001-1006

[4] Aydi, H., Felhi, A. and Karapinar, E., On common best proximity points for generalized $\alpha$ - $\psi$-proximal contractions, J. Nonlinear Sci. Appl., 9 (2016), No. 5, 2658-2670

[5] Chugh, R. and Kumar, S., Common fixed points for weakly compatible maps, Proc. Indian Acad. Sci. (Math Sci)., 111 (2001), 241-247

[6] Dhompongsa, S., Kaewcharoen, A. and Kaewkhao, A., The Dominguez-Lorenzo condition and multivalued nonexpansive mappings, Nonlinear Anal., 64 (2006), No. 5, 958-970

[7] Dontchev, A. L. and Hager, W. W., An inverse mapping theorem for set-valued maps, Proc. Am. Math. Soc., 121 (1994), No. 2, 481-489

[8] Di Bari, C., Suzuki, T. and Vetro, C., Best proximity points for cyclic Meir-Keeler contractions, Nonlinear Anal., 69 (2008), No. 11, 3790-3794

[9] Gecheva, G., Hristov, M., Nedelcheva, D., Ruseva, M. and Zlatanov, B., Applications of Coupled Fixed Points for Multivalued Maps in the Equilibrium in Duopoly Markets and in Aquatic Ecosystems, Axioms, 10 (2021), No. 2,44

[10] Geletu, A., Introduction to topological spaces and set-valued maps (Lecture notes), Ilmenau, Germany: Institute of Mathematics, Department of Operations Research and Stochastics, Ilmenau University of Technology, 2006

[11] Gopi, R., Pragadeeswarar, V., Park, C. and Shin, D. Y., Coupled common best proximity point theorems for nonlinear contractions in partially ordered metric spaces, AIMS Mathematics, 5 (2020), No. 6, 6913-6928

[12] Kamran, T., Coincidence and fixed points for hybrid strict contractions, J. Math. Anal. Appl., 299 (2004), No. 1, 235-241

[13] Lo'lo', P., Vaezpour, SM. and Esmaily, J., Common best proximity points theorem for four mappings in metric-type spaces, Fixed Point Theory Appl., 2015, (2015): 47, 7pp.

[14] Lo'lo', P., Vaezpour, SM. and Saadati, R., Common best proximity points results for new proximal C-contraction mappings, Fixed Point Theory Appl., 2016, No. 56, 10 pp.

[15] Mondal, S. and Dey, LK., Some common best proximity point theorems in a complete metric space, Afr. Mat., 28 (2017), No. 1 85-97

[16] Nadler, S. B., Multi-valued contraction mappings, Pac. J. Math., 30 (1969), No. 2, 475-488

[17] Pragadeeswarar, V., Gopi, R., De la Sen, M. and Radenović, S., Proximally Compatible Mappings and Common Best Proximity Points, Symmetry, 12 (2020), No. 3, 353

[18] Pragadeeswarar, V. and Marudai, M., Best proximity points: approximation and optimization in partially ordered metric spaces, Optim. Lett., 7 (2013), No. 8, 1883-1892 
[19] Pragadeeswarar, V., Poonguzali, G., Marudai, M. and Radenović, S., Common best proximity point theorem for multivalued mappings in partially ordered metric spaces, Fixed Point Theory Appl., 2017, No. 22, 14 pp.

[20] Sadiq Basha, S. and Veeramani, P., Best approximations and best proximity pairs, Acta. Sci. Math., 63 (1997), 289-300

[21] Sadiq Basha, S., Veeramani, P. and Pai, DV., Best proximity pair theorems, Indian J. Pure Appl. Math., 32 (2001), No. 8, 1237-1246

[22] Sadiq Basha, S. and Veeramani, P., Best proximity pair theorems for multifunctions with open fibres, J. Approx. Theory, 103 (2000), No. 1, 119-129

[23] Sankar Raj, V., A best proximity point theorem for weakly contractive non-self-mappings, Nonlinear Anal., 74 (2017), No. 14, 4804-4808

[24] Shayanpour, H., Some results on common best proximity point and common fixed point theorem in probabilistic Menger space, J. Korean Math. Soc., 53 (2016), No. 5, 1037-1056

[25] Sridarat, P. and Suantai, S., Common fixed point theorems for multi-valued weak contractive mappings in metric spaces with graphs, Filomat, 32 (2018), No. 2, 671-680

DEPARTMENT OF MATHEMATICS

AMRITA SCHOOL OF ENGINEERING

Amrita Vishwa VidyapeEtham, CoImbatore-641112, TAmil NadU, India

Email address: v_pragadeeswararecb.amrita.edu (V. Pragadeeswarar)

Email address: r_gopi@cb.amrita.edu (R. Gopi) 